$\mathbb{T}$ periodica polytechnica

Social and Management Sciences

20/1 (2012) $3+10$

doi: 10.3311/pp.so.2012-1.01

web: http://www.pp.bme.hu/so

(c) Periodica Polytechnica 2012

RESEARCH ARTICLE

\section{Cost of capital of energy efficiency projects: The case of space heating and cooling}

Marcell Dülk

Received 2012-01-07

\begin{abstract}
In this paper, we develop and test the hypothesis of zero betas for energy efficiency projects related to space heating and cooling. We focus only on projects using electricity or natural gas and reason that none of their key risk factors has correlations significantly different from zero with the market portfolio or one another, whether the investor is a household or business entity. Supporting evidence from a number of European countries is presented. Our findings suggest that, in the Capital Asset Pricing Model (CAPM) framework, the cost of capital is the risk-free rate. It is argued that this discount rate needs no adjustment for country risk and is likely to be valid for other countries as well as other types of energy efficiency projects using natural gas or electricity.
\end{abstract}

\section{Keywords}

cost of capital $\cdot$ energy efficiency $\cdot$ beta $\cdot$ project $\cdot$ capital budgeting

\section{Acknowledgement}

This work is connected to the scientific program of the "Development of quality-oriented and harmonized $R+D+I$ strategy and functional model at BME" project. This project is supported by the New Széchenyi Plan (Project ID: TáMOP-4.2.1/B09/1/KMR-2010-0002). The author is thankful to György Andor for helpful comments on earlier versions of this paper.

\section{Marcell Dülk}

Department of Finance, BME, 1117 Budapest, Magyar tudósok körútja 2, Hun-

e-mail:dulk@finance.bme.hu
} gary

\section{Introduction}

Energy consumption worldwide has nearly doubled since the 1970s, with fossil fuels still being the fundamental source of energy [16]. The scarcity of natural resources and the consequences of the fossil-dominated energy mix (e.g., pollution, climate change) have placed energy efficiency at the forefront of global challenges. For instance, one of the key objectives of the EU2020 strategy is to reduce the European Union's (EU) energy consumption by $20 \%$ by 2020 . Endeavors are aimed not only at business entities but households as well because the latter group has a share of about $25 \%$ in total final energy consumption in Europe [13]. One particular area of possible energy saving is space heating and cooling. Space heating typically accounts for about $70 \%$ of a household's energy consumption in the EU [21.23]; cooling is rather negligible accounting for less than $1 \%$ [4]. However, the global air conditioning market has been expanding in the last decade and is expected to continue to expand in the coming years [6, 14], raising the importance of cooling energy efficiency. Studies have shown considerable energy-saving potential related to space heating and cooling in both the residential and commercial sectors globally [19,22]. From a technological perspective, space heating and cooling energy can be saved by employing more efficient equipment, such as condensation furnaces, inverter air conditioners, and walls and windows with better thermal insulation, among others. There are, of course, other areas of possible energy saving such as lighting, electrical appliances, and so on. In this paper, however, we focus only on projects that reduce space heating or cooling energy consumption, which are responsible for the majority of residential energy use. We examine also whether there is any difference if a business appraises such projects, because businesses may also be interested in cutting their costs this way.

Replacing the existing technologies with more efficient ones requires capital investment; thus, financial analysis must be conducted to determine if it is worth upgrading. It is often stated that such energy efficiency projects are not profitable by themselves, and therefore, they would not be undertaken without subsidies from either the local government or other organizations such as the EU [1]. It is mainly because the potential cut in energy bills 
is not considered to sufficiently compensate the high price of new technologies. Capital budgeting is most often performed in a discounted cash flow (DCF) framework, in which the expected values of future cash flows are estimated and discounted to their present values by the cost of capital. Thus, the net present value (NPV) of the project is derived, and the project is considered economically favorable and acceptable if its NPV is positive.

Estimating future cash flows is relatively straightforward, but determining the appropriate cost of capital is more problematic; therefore, we focus on this issue in this paper. The cost of capital indicates how much it costs to devote funds to a particular project. It is an opportunity cost because it reflects the benefits lost from other opportunities that are foregone for the sake of the given project. The lost opportunities are considered to be those available in capital markets - more precisely, the expected returns on those investments; hence, the cost of capital is given as an interest rate. However, opportunities in capital markets differ by their riskiness. Therefore, the cost of capital must be the expected return on an investment with risk identical to that of the project. In finance, investors are typically assumed to hold a portfolio of investments. Thus, according to portfolio theory, an asset's risk relevant to the investor is lower than its risk if it is held alone. This means that the perceived, relevant risk of an energy efficiency project is lower in a portfolio than by itself (called total risk) because a portion of the total risk is eliminated in the portfolio. This elimination is attributable to the underlying correlations between the portfolio elements and the project. In this paper, we argue that although space heating/cooling energy efficiency projects might have high total risk, this risk is completely eliminated in a well-diversified portfolio; thus, an investor sees such projects as risk-free opportunities and consequently should employ a risk-free discount rate. Choosing a rate according to the total risk yields a smaller NPV because the cost of capital is in the denominator and is higher for a risky project than a risk-free one. Thus, the profitability of space heating/cooling energy efficiency projects could be significantly undervalued, possibly leading to the erroneous rejection of positive NPV projects.

Estimating the risk of a project is a difficult task. It is known that risk indicates possible deviations from the expected, which, in the case of projects, indicates the possible deviations of future cash flows from their expected values. In our analysis, we start by identifying the cash flows of space heating/cooling energy efficiency projects and their sources of uncertainty. We find that such projects' risk stems fundamentally from the variability of energy bills, which are comprised of two principal elements: energy consumption (which depends on the weather) and energy prices. We examine natural gas (henceforth: gas) and electricity prices as two important energy carriers used for heating/cooling purposes. Then, we discuss what effects the weather and price uncertainties have in the Capital Asset Pricing Model (CAPM), which is a generally applied framework for cost of capital estimation. Based on data from a number of European countries, we show that the appropriate discount rate should be the riskfree rate for both households and businesses and argue that the same conclusion is likely to be drawn for projects in other countries as well as for other types of energy efficiency projects.

\section{Cash flows of space heating/cooling energy effi- ciency projects}

An energy efficiency project typically means replacing existing technology with a better one. This implies the following cash flows, which are listed chronologically:

- Investment in the new technology (includes price of equipment and installation costs)

- Salvage value of existing technology

- Difference in operation and maintenance costs (O\&M)

- Difference in taxes

- Savings in energy bills

- Salvage value of the new technology

As noted earlier, the initial investment in the new technology may be large. It might be partly offset by the salvage value of existing technology, but there is often no such value because it cannot be sold (e.g., old thermal insulation material). The difference between the O\&M costs of the old and new equipment can well be regarded as negligible. Taxes are the particular elements that make the distinction between a household's and a business' perspective: Households have to pay everything in gross terms (that is, including value-added tax (VAT)), whereas for general businesses, only the net amount is relevant. However, businesses have to pay other types of taxes, e.g., corporate taxes, which are affected by the project through the depreciation of new technology and cost reduction. The way corporate taxes are calculated depends on a country's legislation, which is largely unique to that particular country. Therefore, we omit any specific calculation example and the tax effects for businesses to provide a more generally valid discussion. The savings in energy bills are probably the most crucial among the cash flows because they represent the major source of cash inflows. We note here that for households, the difference in taxes is incorporated into the energy cost savings because households pay the bills in gross terms. The salvage value of the new technology at the end of its life can also be neglected similarly to the old one or can be accounted for only in the decision about a later upgrade as the then-existing technology.

Now that the list of cash flows is assembled, we can assess the risks associated with them. The initial investment and salvage value of existing technology (if any) are paid upfront at the beginning of the project and thus do not affect profitability over the project's life-span. Difference in O\&M costs is paid over time but is assumed to be negligible. Taxes may change if the tax regime changes - we argue that this does not happen often 
or to a significant extent, and thus, this risk factor can also be neglected. The salvage value of the new technology can also be omitted for reasons previously mentioned. The one item remaining is the energy bill, which has the greatest impact on the attractiveness of the project. As noted in the introduction, the annual savings depend on the amount of consumption on the one hand, which is a function of the weather, i.e., how cold the winter or how hot the summer is. On the other hand, savings depend on the price of energy, which may change considerably over time.

Heating and cooling energy consumption is influenced mainly by the following factors: the difference between the desired indoor and the actual outdoor temperature, the construction of the building, and the efficiency of the equipment used. Usually, all of these parameters are constant or can at least be regarded as constant over time, except for the actual outdoor temperature, which varies continuously according to climate characteristics. This means that one source of project risk is the uncertainty related to the outdoor temperature. We note here that there are relatively easy-to-use engineering models (see, e.g., [11] for illustration) that apply Gaussian normal distribution to the outdoor temperature to estimate energy consumption.

Determining the price of energy is not as simple as it may seem. As noted earlier, we focus only on two groups of prices: gas and electricity. The price the end-user pays for these energy types is comprised mainly of two elements: the price of energy itself and the fee of delivering it to the end-user, i.e., distribution fees. The distribution network is, in most cases, operated as a natural monopoly; thus, such fees are regulated. This means that there is a somewhat uniform price component, which relatively seldom changes. The price of energy itself may also fall under regulation, as is often the case with households, but it may also be a market price shaped by supply and demand. The fact that there are many sorts of energy "products" traded makes the picture more complex. For example, there are forward contracts, which sell gas or electricity months or years in advance. There is obviously a different price for the same $\mathrm{kWh}$ sold one year or two years ahead; moreover, the price for the same product varies by exchanges. Because electricity cannot be stored, its pricing is more complicated than that of natural gas. Furthermore, energy traders, who sell the energy to end-users, purchase a multitude of different products and typically give a unique quotation according to each client's own consumption characteristics. We do not intend to go into more detail about the pricing of energy carriers, and therefore, we point out only two key difficulties: it is not unequivocal which product's price to use for analysis; and there is usually a unique price for each consumer. We believe that the best way to bridge these problems in our case is to determine an average "typical" price charged in the past. This means first identifying a group of consumers deemed to be representative and then collecting data on the prices they paid. Such international samples have been collected by, e.g., the International Energy Agency (IEA) and Eurostat. We argue that such prices provide a fair approximation of gas and electricity prices relevant to space heating/cooling energy efficiency projects.

Now that the factors of uncertainty have been established, we examine how they influence the project's cost of capital.

\section{Cost of capital of space heating/cooling energy effi- ciency projects}

\subsection{Theoretical background}

As outlined in the introduction, the risk of any asset is to be analyzed as part of a portfolio and not by itself - except in special cases, when investors cannot or do not want to hold portfolios. Theory holds that combining different securities into a portfolio offers risk-reduction opportunities with possibly no sacrifice of return. This is called diversification, and if the creation of portfolios is free of costs, then a rational investor does diversify. In practice, there are costs associated with diversification, e.g., transaction costs of buying securities, but they are typically small, and therefore, holding many investments is still desirable. The return on risky investments is commonly assumed to be normally distributed; thus, an investment is defined by its expected return and the standard deviation of the return, which indicates its risk. This is also referred to as mean-variance framework. A portfolio of any $n$ pieces of investment opportunities is then characterized as follows:

$$
\begin{array}{r}
E\left(r_{P}\right)=\sum_{i=1}^{n} a_{i} E\left(r_{i}\right), \quad \text { and } \\
\sigma\left(r_{P}\right)=\sqrt{\sum_{i=1}^{n} a_{i}^{2} \sigma^{2}\left(r_{i}\right)+2 \sum_{i, j}^{n, n} k_{i, j} a_{i} a_{j} \sigma\left(r_{i}\right) \sigma\left(r_{j}\right),}
\end{array}
$$

with the conditions $\sum_{i=1}^{n} a_{i}=1$, and $i \neq j$, and $i, j \neq j, i$

where $i$ and $j$ are indices for securities in the portfolio $P$, and $a$ denotes the weight in the portfolio, $E(r)$ denotes the expected return, $\sigma(r)$ denotes the standard deviation, and $k_{i, j}$ denotes the correlation between investment $i$ and $j$.

Eq. (1) shows that if $k_{i, j}=1$ for every pair of $i$ and $j$, then no risk can be diversified away, and the risk of the portfolio is simply the weighted average of the standard deviations of the individual investments. However, correlations other than 1 provide incentive for diversification, and investors would combine all available investments to take full advantage of diversification. It can be shown that the smaller correlation an investment has with the other assets, the greater risk-reduction benefits it provides. The portfolios that offer the highest possible expected return for a given level of risk or, equivalently, offer a given expected return for the lowest possible risk are called efficient portfolios.

The Capital Asset Pricing Model (CAPM) was formulated on the foundations of portfolio theory with the critical assumption, among others, that investors hold an efficient portfolio; in particular, a combination of the risky market portfolio and a risk-free 
investment. The composition of the market portfolio is the same for every investor and contains all the available investments in the world with the same weights as they are represented in the world. The risk-free investment is, in practice, approximated mostly by U.S. treasury bills. The CAPM states that there is a linear relationship between any security's expected return and its risk (graphically referred to as the security market line (SML)):

$$
E\left(r_{i}\right)=r_{f}+\beta_{i}\left(E\left(r_{M}\right)-r_{f}\right)
$$

where $r_{f}$ is the risk-free rate, $E\left(r_{M}\right)$ is the expected return on the market portfolio $M$, and $\beta_{i}$ is the risk parameter of investment $i$.

The most crucial parameter of the CAPM is $\beta$, which determines the relevant risk of the investment. As mentioned earlier, in the CAPM, investors hold combinations of the risk-free investment and the market portfolio. The risk-free asset has zero correlation with the other assets and zero standard deviation, and therefore, it is not involved in diversification. Thus, in the CAPM, each investment opportunity is evaluated according to its impact on the risky market portfolio. The relevant (systematic) risk of an investment is that portion of its total risk that is not diversified in the market portfolio. This is determined by the correlation between the given asset and the market portfolio, as follows from Eq. (1). We note that in this theoretical framework, every asset is already part of the market portfolio, and therefore, comparing individual securities to the market is a simplification but is considered an acceptable approximation. Mathematically, the beta parameter of any investment is calculated as

$$
\left[\beta_{i}=k_{i, M} \frac{\sigma\left(r_{i}\right)}{\sigma\left(r_{M}\right)},\right]
$$

[ the relevant risk being $\sigma\left(r_{i}\right)_{\text {relevant }}=\beta_{i} \sigma\left(r_{M}\right)$ ]

Because the cost of capital $\left(r_{a l t}\right)$ is the expected return of a capital market investment with identical risk, it is then given in the CAPM framework as

$$
r_{a l t}=r_{f}+\beta_{\text {project }}\left(E\left(r_{M}\right)-r_{f}\right)
$$

In financial practice, there is good consensus on the values of $r_{f}$ and $E\left(r_{M}\right)$, which are annually about $2 \%$ and $8 \%$, respectively, in real terms [3]. Thus, practically, the beta of a project is the only parameter that needs to be determined to determine the cost of capital.

\subsection{The zero-beta hypothesis of space heating/cooling en- ergy efficiency projects}

As Eq. (3) shows, $\beta$ is estimated from three parameters: the standard deviations of the return on the market portfolio and that of the project and the correlation between the two. These parameters reflect future expectations, but in practice, the betas of securities are calculated from historical data, with the assumption that the past is a good predictor for the future. Calculating the beta of public companies is a relatively simple task because there is usually a sufficiently long time series of past stock returns. There are also several indices available through which the market portfolio can be approximated. Projects, however, are not traded publicly, and therefore there are no price data available from which returns could be calculated. In financial practice, a project's beta is often estimated by taking an average of betas of public firms with risk characteristics similar to the given project, which typically means firms in industries similar to the project [5, 8]. In our case, this suggests taking the average beta of firms in the energy sector or, more narrowly, that of electricity or gas companies. We argue that this approach yields a distorted estimate in our case because energy companies are more exposed to some risks to which our project is less exposed (e.g., from human resources, suppliers, and prices of other resources) and conversely may be less exposed to other risks that affect our project more (e.g., due to protection by regulation and governmental aid). In this paper, we do not aim to exactly quantify the beta of a given space heating/cooling energy efficiency project. We argue that the beta of such projects should be taken zero, in contrast to the positive betas suggested by those of energy companies.

To test the hypothesis of a zero project beta, we focus on the correlation term in Eq. (3). If the correlation coefficient is zero, then the beta of the project is also zero. Correlation refers to the stochastic relationship between the return on the project and the return on the market portfolio. As noted earlier, unfortunately, there are no historical return data for our projects. However, there are data available for energy prices and weather, which represent the main sources of risk in space heating/cooling energy efficiency projects. We can state that if we find no correlation between any risk factor and the market portfolio or between any two risk factors, then the overall correlation of the project must also be zero. In our case, this requires the examination of three correlations: between gas/electricity consumption and the market portfolio, between the price of gas/electricity and the market portfolio, and between gas/electricity consumption and the price of gas/electricity.

\subsubsection{Energy consumption and weather equivalency as- sumption}

Unfortunately, there are no data publicly available regarding individual consumption in the past, from which correlations could be calculated. There are, however, detailed records on temperature, which could be used alternatively. Working with weather data instead of actual consumptions yields the same correlation results only if the two correlate perfectly with one another. This might not be the case if consumption is influenced by factors other than the weather. In fact, energy prices may have an impact on consumption, e.g., if the price of gas goes up, we may be inclined to heat less. However, it can be hypothesized that the amount of energy used for heating/cooling purposes is rather independent of prices because climatic comfort is considered a necessity, a price-inelastic good. This is supported by, 
e.g., the empirical study by Lee and Lee [18], who show that the total energy and electricity demands are price-inelastic in OECD countries. Liu [20] also confirms the inelasticities of natural gas and electricity demands, reporting that industrial consumers are more insensitive to price. Another supporting argument is that even if energy consumption is somewhat affected by energy price, it is probably dominantly more sensitive to climatic conditions. In conclusion, we make the assumption that energy consumption depends only on the weather; therefore, they correlate equivalently with any other variable. Consequently, in the next sections, we examine the relationship between energy prices, the market portfolio, and the weather.

\subsubsection{Correlation of the weather and the market portfolio}

It seems plausible that financial processes have no impact on outdoor temperature and conversely, that weather in any country has no impact on the world economy. Therefore, no correlation can be assumed without any calculation. Calculations in this respect are also unnecessary because a coefficient significantly different from zero could be accidentally measured, which would contradict common sense, as explained. Here, we note that this is also the reason for not measuring the correlation between hypothesized past energy bills and the market, although the variability of the project stems from the variability of energy bills. Calculating the correlation between energy bills and the market portfolio could provide false, misleading results because of the involvement of the weather. We remark, however, that a recent study by Yang et al. [24] showed zero or little correlation among international weather indices and stock market indices, which supports our independence hypothesis.

\subsubsection{Correlation of energy prices and the market portfolio}

To determine the correlation of gas and electricity prices with the market, we use the MSCI World Index in U.S. dollars as the proxy for a global market portfolio. The end-user energy prices are taken from the Eurostat database, which provides a collection of semi-annual prices (observed January 1 and July 1 every year) for various consumer groups, separately for domestic and industrial consumers. These prices are total prices, including distribution fees, the price of energy itself, and any related taxes. Data for years prior to 1991 provide prices only for the first semesters; therefore, we work with data starting from 1991. The method of data collection was changed in 2007; therefore, we use data for the 1991-2007 period to have a consistent time series. For households, we take the electricity prices of group "Dc" and gas prices of group "D3" in euros, with all taxes included. For businesses, we take the electricity prices of group "Ie" and gas prices of group "I3-1" in euros, excluding VAT. We choose these groups because they provide the largest number of observations and can be regarded as a fair approximation of an average consumer. We note here that although we previously argued for the negligibility of tax risks, we decide to include them for households because all such risks can be easily observed by simply considering gross prices. This is the reason why domestic consumer prices including all taxes are used.

For our analysis, we select those European countries that have at least 30 out of the 34 maximum possible observations. The following nine countries meet this requirement: Germany, France, United Kingdom, Italy, Belgium, Spain, Luxembourg, the Netherlands, and Hungary. We convert prices to U.S. dollars using the average exchange rates for January and July in Eurostat. Then, we consider gas and electricity as investments and calculate the real log returns on them and on the market according to Eq. (3):

$$
\left(\ln p_{t}-\ln p_{t-1}\right)-\left(\ln C P I_{t}-\ln C P I_{t-1}\right)=r_{t, \text { real }}
$$

where $p_{t}$ is the price of gas or electricity or the value of the market index for semester $t ; C P I_{t}$ is the consumer price index "CPI-U, all urban consumers, U.S. city average, all items" for semester $t$, provided by the Bureau of Labor Statistics, U.S. Department of Labor; and $r_{t, \text { real }}$ is the real $\log$ return in semester $t$. We note that the market index and CPI data are freely available as of the ends of months, whereas energy prices are available as of the beginnings of the given months. Therefore, as the closest approximation, we pair January 1 energy prices with the previous year's end-of-December market index and CPI, and July 1 prices with the same year's end-of-June market index and CPI. In the cases of missing data, we use simple listwise deletion.

Table 1 summarizes the correlations between the real log returns on the market portfolio and energy prices.

As Table 1 shows, all of the coefficients are small, and none of them are significantly different from zero at the customary levels of either 0.05 or 0.10 ; therefore, the null hypothesis of no correlation should be accepted in all cases. It is to be added that the sample size is rather limited, which may raise concerns about the power of the test, namely, accepting the null hypothesis when it is actually false and thus making a type II error. The above correlation estimates are based on no fewer than $31 \mathrm{ob}-$ servations, except for the Netherlands business figures. Allowing for two tails at a 0.05 significance level, the test is powerful enough (with a power of 0.80 ) for true population correlations below -0.46 and above 0.46 for a sample size of 31 . If the significance level is relaxed to 0.10 , then the test is powerful for coefficients below -0.41 and above 0.41 . However, our sample size is given, and we work with the largest possible sample, and therefore, there is nothing more we can do about the type II error in this respect. Further research should be conducted to determine if the current power of the test is sufficient, i.e., true correlations ranging between approximately -0.40 and 0.40 are within the tolerance limits.

\subsubsection{Correlation of energy prices and the weather}

We mentioned in the introduction that air conditioning is responsible for only a negligible share in energy consumption. Thus, an increase in the demand for cooling is unlikely to have any effect on energy prices. Prices clearly have no impact on 
Tab. 1. Correlation coefficients of real log returns on domestic and industrial gas and electricity prices in selected European countries measured against the real log returns on the MSCI World Index for the 1991-2007 period. Two-tailed $p$-values are provided in parentheses.

\begin{tabular}{|c|c|c|c|c|}
\hline & \multicolumn{2}{|c|}{ Households } & \multicolumn{2}{|c|}{ Businesses } \\
\hline & Electricity & Gas & Electricity & Gas \\
\hline \multirow[t]{2}{*}{ Germany } & 0.007 & -0.010 & -0.111 & -0.104 \\
\hline & $(0.969)$ & $(0.956)$ & $(0.547)$ & $(0.564)$ \\
\hline \multirow[t]{2}{*}{ France } & 0.035 & -0.129 & 0.001 & 0.005 \\
\hline & $(0.848)$ & $(0.476)$ & $(0.995)$ & $(0.978)$ \\
\hline \multirow[t]{2}{*}{ United Kingdom } & 0.169 & 0.182 & 0.177 & -0.007 \\
\hline & $(0.346)$ & $(0.311)$ & $(0.333)$ & $(0.968)$ \\
\hline \multirow[t]{2}{*}{ Italy } & 0.151 & 0.049 & 0.027 & 0.066 \\
\hline & $(0.400)$ & $(0.790)$ & $(0.881)$ & $(0.718)$ \\
\hline \multirow[t]{2}{*}{ Belgium } & 0.098 & -0.096 & -0.012 & 0.009 \\
\hline & $(0.587)$ & $(0.608)$ & $(0.947)$ & $(0.959)$ \\
\hline \multirow[t]{2}{*}{ Spain } & 0.038 & -0.001 & 0.125 & -0.075 \\
\hline & $(0.841)$ & $(0.995)$ & $(0.503)$ & $(0.687)$ \\
\hline \multirow[t]{2}{*}{ Luxembourg } & -0.025 & -0.053 & 0.086 & -0.064 \\
\hline & $(0.892)$ & $(0.778)$ & $(0.639)$ & $(0.732)$ \\
\hline \multirow[t]{2}{*}{ The Netherlands } & 0.070 & 0.053 & 0.157 & -0.059 \\
\hline & $(0.702)$ & $(0.792)$ & $(0.454)$ & $(0.750)$ \\
\hline \multirow[t]{2}{*}{ Hungary } & 0.019 & 0.019 & 0.095 & -0.211 \\
\hline & $(0.920)$ & $(0.920)$ & $(0.613)$ & $(0.255)$ \\
\hline
\end{tabular}

the weather; therefore, in the case of cooling, these two variables are independent, and consequently, there is no correlation between the two.

The case of heating is not as straightforward because it accounts for a vast share in consumption. Therefore, we test if any reasonable positive correlation can be found between gas or electricity prices and the coldness of the weather. We use the heating degree-days (HDD) as the proxy for the demand for heating, with a higher HDD indicating colder weather. In particular, we consider monthly data on actual heating degree-days from Eurostat (noted as ADD in the database) and sum them up for each half-year, i.e., January to June and July to December, to arrive at comparable semi-annual data for the 1991-2007 period. Because the periodicity of the weather is a year, annual changes are to be examined. Insisting on calendar years would cut our sample size in half, thus largely reducing the power of the test. To maintain the largest possible sample size while keeping the annual scope, we suggest that annual changes are recalculated semi-annually. This approach is similar in spirit to that of Erdős and Ormos [12]. We use the following formula:

$$
\ln \left(x_{t}+x_{t-1}\right)-\ln \left(x_{t-2}+x_{t-3}\right)=r_{\text {annual }, t}
$$

where $x$ is the real (CPI-corrected) price of gas or electricity in U.S. dollars or semi-annual ADD for semester $t$ and $r_{\text {annual, } t}$ is the annual change for semester $t$.

Eq. (6) reflects the log difference of average prices, but it should be noted that division by 2 is omitted because of mathematical equivalence. We measure the correlation between the derived real log returns on annual average energy prices and the corresponding log differences of annual heating degree-days for the same group of European countries. We examine both gas and electricity prices because either can be used for heating purposes; however, their share may vary by country. The coefficients are expected to be positive if different from zero because a higher demand (i.e., higher ADD) is expected to provoke an increase in prices, ceteris paribus. Therefore, we perform a onetailed test of significance. Missing data are again treated with listwise deletion. Table 2 summarizes the results.

Tab. 2. Correlation coefficients of semi-annually calculated annual real log returns on domestic and industrial gas and electricity prices in selected European countries measured against the semi-annually calculated log differences of annual actual heating degree-days (ADD) for the 1991-2007 period. One-tailed $p$-values are provided in parentheses. $*, * *$, and $* * *$ denote significance at the $0.10,0.05$, and 0.01 level, respectively.

\begin{tabular}{|c|c|c|c|c|}
\hline & \multicolumn{2}{|c|}{ Households } & \multicolumn{2}{|c|}{ Businesses } \\
\hline & Electricity & Gas & Electricity & Gas \\
\hline \multirow[t]{2}{*}{ Germany } & 0.100 & 0.038 & 0.097 & -0.011 \\
\hline & $(0.300)$ & $(0.419)$ & $(0.304)$ & $(0.477)$ \\
\hline \multirow[t]{2}{*}{ France } & 0.126 & 0.036 & 0.118 & -0.028 \\
\hline & $(0.249)$ & $(0.424)$ & $(0.263)$ & $(0.441)$ \\
\hline \multirow[t]{2}{*}{ United Kingdom } & $-0.494^{\star * *}$ & $-0.524^{\star * *}$ & -0.208 & $-0.448^{\star * *}$ \\
\hline & $(0.002)$ & $(0.001)$ & $(0.135)$ & $(0.007)$ \\
\hline \multirow[t]{2}{*}{ Italy } & -0.122 & -0.200 & $-0.242^{*}$ & $-0.296^{*}$ \\
\hline & $(0.256)$ & $(0.144)$ & $(0.095)$ & $(0.056)$ \\
\hline \multirow[t]{2}{*}{ Belgium } & 0.086 & 0.127 & 0.036 & 0.006 \\
\hline & $(0.322)$ & $(0.264)$ & $(0.423)$ & $(0.487)$ \\
\hline \multirow[t]{2}{*}{ Spain } & -0.007 & -0.097 & 0.008 & $-0.434^{\star *}$ \\
\hline & $(0.487)$ & $(0.315)$ & $(0.485)$ & $(0.012)$ \\
\hline \multirow[t]{2}{*}{ Luxembourg } & 0.179 & 0.078 & 0.052 & 0.096 \\
\hline & $(0.172)$ & $(0.349)$ & $(0.393)$ & $(0.317)$ \\
\hline \multirow[t]{2}{*}{ The Netherlands } & 0.127 & 0.028 & -0.029 & -0.013 \\
\hline & $(0.253)$ & $(0.442)$ & $(0.451)$ & $(0.476)$ \\
\hline \multirow[t]{2}{*}{ Hungary } & 0.123 & -0.010 & 0.165 & -0.052 \\
\hline & $(0.262)$ & $(0.480)$ & $(0.196)$ & $(0.395)$ \\
\hline
\end{tabular}

As Table 2 shows, the coefficients are again not significantly different from zero, except in six cases: three for the UK, two for Italy, and one for Spain. However, in these six cases, the correlation is negative, which reflects a contradiction. Only a positive coefficient is meaningful, and therefore, we discard these results. The caveats made earlier in connection with the power of the test apply here as well: the sample size is not smaller than 27 for these estimates, except for the business figures from the Netherlands. Here, however, we use a one-tailed test, which is powerful enough (with a power of 0.80 ) at a 0.05 significance level for true population correlations of 0.44 and above for a sample size of 27 . If the significance level is relaxed to 0.10 , 
then the test is powerful for coefficients greater than or equal to 0.38. As shown, the test has slightly better power despite the smaller sample size due to being one-tailed. Again, the sample size is given, and therefore, we make the best possible estimate, which suggests no correlation between energy prices and the weather.

\section{Discussion of the results}

Summarizing our results, we find no statistically significant correlation between gas or electricity prices, the weather, and the market portfolio. Consequently, the beta of space heating/cooling energy efficiency projects should be assumed to be zero for both households and businesses. Substituting it into Eq. (4) yields the risk-free rate as the cost of capital, which is approximately $2 \%$ annually, in real terms. On the contrary, industry betas [10] suggest the following rates: $6.68 \%$ for power with a beta of $0.78,4.94 \%$ for electric utilities with a beta of 0.49 , and $4.70 \%$ for natural gas utilities with a beta of 0.45 . Using these discount rates would understate the value of space heating/cooling energy efficiency projects. The magnitude of understatement for a $5 \%$ discount rate versus $2 \%$ is approximately $25 \%$ for a 20 -year annuity and approximately $30 \%$ for a 20 -year annuity growing at $5 \%$ per annum (to account for possibly increasing energy prices). These magnitudes may indeed make a difference in project appraisal and in deciding on the amount of necessary subsidies.

Now, we consider the validity of our results. First, we conducted the analysis assuming that the CAPM as a model is true. This is more commonly accepted for developed countries, but Andor et al. [2] present evidence from Hungary that even in a small country with a young capital market the CAPM can still be valid. The findings of the authors are basically unchanged if a global or local market index is used. This implies that our results may apply even to relatively segmented investors who hold "local efficient" portfolios. Nonetheless, the zero-beta hypothesis holds only for well-diversified investors.

Another point is that we analyzed only energy efficiency projects that would be undertaken in certain European countries, which raises two important issues: that of country risk premium and the applicability of results in other countries.

It is discussed in finance textbooks that investments in foreign countries are exposed to specific (e.g., political) risks, which should be accounted for. This is preferably accomplished through the adjustment of the discount rate, increasing it in the case of riskier countries. It should be noted that any adjustment for country risk premium is relevant only if the country risk is not diversifiable, which is still a subject of debate. There is, more or less, a practical consensus towards adjustment due to the interdependence of countries in the era of globalization [9]. Our results, however, need no adjustment because we compared all of the relevant risk factors in each country directly to a global market portfolio, thus exactly capturing the relevant risk a globally diversified investor would perceive from hold- ing such a project. In other words, the risk factors we measured already contain all uncertainty specific to the particular country, including any country-specific risks, and their correlation with the market reflects just the relevant risk for a globally diversified investor.

Although our results are based on data from selected European countries, we argue that the same conclusions can be drawn for other countries. First, the return on the market portfolio is presumably uncorrelated with the weather in any other country. Second, heating and cooling energy consumption represent only a portion of the total national consumption, thus probably having a similarly weak impact on energy prices in other countries as well. Third, a significant proportion of end-user electricity and gas prices may be determined by regulation (e.g., distribution fees) and not by market forces. Additionally, some studies [7, 15] examining the relationship between market indices and oil prices find no systematic relationship. Kilian and Vega [17] find no convincing evidence that energy prices react to macroeconomic news in the United States. Because oil may be regarded as the most influential energy carrier, these findings are likely to apply to gas and electricity as well.

Finally, our conclusions can be extended to other types of energy efficiency projects. For example, the same results likely apply to the case of lighting, whether in a residential or public context. The amount of time during which lights are switched on in homes or in a park is independent of the world economy and is presumably uncorrelated with electricity prices because it is a price-inelastic good. The same argument can be applied to TVs, washing machines, and other appliances.

Following the arguments above, the hypothesis can be made that any energy efficiency project using gas or electricity has a zero beta in any country, and the cost of capital of the project is the risk-free rate, which needs no adjustment for country risk. Even if there is a small correlation between risk factors, the riskfree rate might still be a better approximation than industry betas. However, these are only hypotheses and require empirical testing to be confirmed.

\section{Conclusions}

In this paper, we developed the hypothesis of zero betas for space heating and cooling energy efficiency projects. We hypothesized that although such projects may have high total risk, it is completely eliminated in the market portfolio. Thus, the cost of capital is the risk-free rate for a well-diversified investor. In support of this theory, we first identified the relevant cash flows of space heating/cooling energy efficiency projects and their sources of uncertainty. We found that two components of energy bills have the most impact on project risk: one is the weather, which determines heating/cooling energy consumption, and the other is the price of energy. Having made the assumption that energy consumption depends only on the weather, we presented arguments that zero correlation should be considered between the market portfolio and the weather, and in a num- 
ber of European countries, we found no statistically significant correlation between gas or electricity prices and the market portfolio, and between gas or electricity prices and heating degreedays used as a proxy for heating energy consumption. Because none of the risk factors correlate with the market or one another, we established that returns on the project must also have zero correlation with the market; consequently, the project's beta is zero. We found this to be true for both households and businesses appraising such projects. We argued that our results need no adjustment for country risk and hypothesized that the same conclusion of a zero beta is likely to be drawn in other countries as well. Moreover, we presumed that our results are valid for other types of energy efficiency projects as well. The extensibility of our findings, however, requires further empirical testing to be confirmed.

\section{References}

1 Amstalden R W, Kost M, Nathani C, Imboden D M, Economic potential of energy-efficient retrofitting in the Swiss residential building sector: The effects of policy instruments and energy price expectations, Energy Policy 35 (2007), no. 3, 1819-1829, DOI 10.1016/j.enpol.2006.05.018.

2 Andor Gy, Ormos M, Szabó B, Empirical tests of Capital Asset Pricing Model (CAPM) in the Hungarian capital market, Periodica Polytechnica Social and Management Sciences 7 (1999), no. 1, 47-64.

3 Andor Gy, Tóth T, Vállalati pénzügyi elemzések APV-módszerrel (Corporate financial analysis with APV method), Typotex, Budapest, 2009.

4 Atanasiu B, Bertoldi P, Electricity consumption and efficiency trends in the enlarged European Union - Status report 2006, European Commission Directorate-General, Joint Research Centre, Institute for Environment and Sustainability, 2007, available at www.jrc.ec. europa.eu

5 Brealey A, Myers S, Principles of Corporate Finance, McGraw-Hill Book Co., New York, NY, 1996. fifth ed.

6 BSRIA - Building Services Research and Information Association, Review of the World Air Conditioning Market 2007, 2008, available at www. bsria.co.uk/news/1997/[04-07-2011]

7 Chen N-F, Roll R, Ross S A, Economic forces and the stock market, Journal of Business 59 (1986), no. 3, 383-403, DOI 10.1086/296344.

8 Damodaran A, Investment Valuation - Tools and techniques for determining the value of any asset, John Wiley \& Sons, Inc., New York, NY, 2002. second ed.

$9 \_$, Country risk and company exposure: Theory and practice, Journal of Applied Finance 13 (2003), no. 2, 63-76.

$10 \ldots$, Levered and Unlevered Betas by Industry, 2011, available at www . stern.nyu.edu/ adamodar/pc/datasets/betas.xls [04-07-2011]

11 Dülk M, Klímaberendezés-beruházások múszaki modellezése (Technical modelling of air conditioning projects), Energiagazdálkodás 51 (2010), no. 6, 7-9.

12 Erdős P, Ormos M, Return calculation methodology: Evidence from the Hungarian mutual fund industry, Acta Oeconomica 59 (2009), no. 4, 391 409.

13 Eurostat, Energy, transport and environment indicators, 2010, available at ec. europa.eu/Eurostat

14 GIA - Global Industry Analysts Inc., Air Conditioning Systems Market Report, 2010, available at wWw. strategyr. com

15 Huang R D, Masulis R W, Stoll H R, Energy shocks and financial markets, Journal of Futures Markets 16 (1996), no. 1, 1-27, DOI 10.1002/(SICI)10969934(199602)16:1<1::AID-FUT1>3.0.CO;2-Q.

16 IEA - International Energy Agency, Key World Energy Statistics, 2010, available at www.iea.org
17 Kilian L, Vega C, Do energy prices respond to U.S. macroeconomic news? A test of the hypothesis of predetermined energy prices, Review of Economics and Statistics 93 (2011), no. 2, 660-671, DOI 10.1162/REST_a_00086.

18 Lee C C, Lee J D, A panel data analysis of the demand for total energy and electricity in OECD countries, Energy Journal 31 (2010), no. 1, 1-23, DOI 10.5547/ISSN0195-6574-EJ-Vol31-No1-1.

19 Levine M, Ürge-Vorsatz D, Blok K, Geng L, Harvey D, Lang S, Levermore G, Mongameli Mehlwana A, Mirasgedis S, Novikova A, Rilling J, Yoshino H, Residential and commercial buildings, Climate Change 2007: Mitigation. Contribution of Working Group III to the Fourth Assessment Report of the Intergovernmental Panel on Climate Change, 2007.

20 Liu G, Estimating energy demand elasticities for OECD countries $-A d y$ namic panel data approach, 2004. Discussion Papers No. 373, Statistics Norway, Research Department.

21 Market observatory for energy, REPORT 2009 Europe's energy position - markets $\mathcal{E}$ supply, 2010, available at wWw. energy. eu/publications

22 Novikova A, Urge-Vorsatz D, Potentials and costs of carbon dioxide mitigation in the world's buildings, Energy Policy 36 (2008), no. 2, 642-661.

23 Odyssee-Mure project, Energy efficiency trends and policies in the EU27 - Results of the Odyssee-Mure project, Paris, 2009, available at WwW. odyssee-indicators.org

24 Yang C C, Li L S, Wen M M, Weather risk hedging in the European markets and international investment diversification, Geneva Risk and Insurance Review 36 (2011), no. 1, 74-94, DOI 10.1057/grir.2010.4. 